often much more strongly developed and the creatures them selves much larger than the fresh-water forms, and the manipulation is therefore somewhat more difficult. The marine forms are also more apt to be incrusted with foreign bodies, bored by predatory sponges, like Cliona, or even by other mollusks, or perforated by certain annelids which have the power to dissolve the lime of which the shell is composed, and in this way secure a retreat for themselves.

Shells which do not contain the living animal are frequently occupied by hermit crabs or by tubicolous annelids. The latter fill up the larger part of the spire with consolidated sand or mud, in the centre of which they have their burrow. The hermit crabs do not add anytbing to the shells which they occupy, but, on the contrary, by their constant motion are apt to wear away the axis or pillar of the shell, so that often a specimen of this sort may be very fairly preserved and yet on the pillar show characters entirely different from those which one would disco:er in a specimen which had never been occupied by a crab. A shell which the crab has selected for its home is often taken possession of, as far as the outside is con cerned, by a hydractinia, a sort of polype, which produces a horny or chitinous covering which is very difficult to remove from the shell to which it is attached. As the hydractinia grows it finally covers the whole shell, to some extent assumes its form, and then, if the creature has not attained its full growth, this is apt to take place around the edlges of the aperture, which are continued by a surt of leathery prolongation which arsumes in a rough way the form of a shell. The crab, when he grows too large for the shell in which he has ensconced himself, is usually obliged to abandon it and find a larger one, which is always a difficult and more or less dangerous operation; but if his shell is overgrown by the polype referred to, it often happens that the polype and the crab grow at about an equal rate, so that the latter finds himself protected and does not have to make a change. It is supposed that the polype profits to some extent by the microscopic animals attracted by the food or $\mathrm{cx}$. crement of the crab, so that this joint housekeeping is mutually beneficial, and, for such cases, since the word pariasite would not be strictly accurate, the word commensal has been adopted. These modified shells often assume very singular shapes. The polype is able in the course of time to entirely dissolve the original calcareous shell upon which its growth began, so that if the spire be cut through it would be found throughout of a horny or chitinous nature. Some of the older naturalists were deceived by forms of this sort and applied name: to them, supposing that they were really molluscan shells of a very peculiar sort.

In removing the animal matter from the shell of large gas tropods it will often require a good deal of time and care to get out all the animal matter from the spire, but it is well worth while to take the trouble, as the presence of such matter forms a constant attraction for museum pests of all descriptions. A medium-sized syringe is convenient for washing out the spire of such shell:. The ordinary marine gastropods may be treated in a general way like the fresh-water gastropods. There are, however, abnormal forms, especially among tropical species, which require particular attention. Some species become affixed to corals and overgrown by them, retaining only a small aperture through which the sea water can reach the prisoner. Such specimens are best exhibited by retaining a part of the coral and cutting the rest away, showing at once the mode of occurrence and the form of the covered shell. Borers are always more difficult to handlc and prepare for the cabinet than other mollusks. They are usually more or less modified for their peculiar mode of life, and frequently rely upon their burrow as a protection, so that the shell is reduced, relatively to the animal, to a very small size. Most of these forms are best kept in alcohol. The hard parts may properly be represented in the cabinet by other specimens. Some of the bivalves, such as the American "soft clam," possess very long siphons, covered with a horny epidermis, and it hecomes a question as to whether an attempt should be made to preserve this epider mis in the cabinet or not. The writer has seen very nicely prepared specimens in which the fleshy portions had all been taken out and replaced by cotton, so that the epidermis of the slphon retained its original position and form; but such specimens are always very delicate, easily broken, and liable to attack by insects, so that it would seem hardly worth while to go to the trouble, when specimens may be preserved completc in alcohol showing all the features referred to. Boring shell fish, like l'holus, frequently have accessory pieces, which are liable to be lost when the soft parts are removed unless care is taken to avoid it. Other bivalves have the internal ligament reinforced by a shelly plate, which is called the ossiculum. This is very easily detached and lost, and, being an object of great interest, special pains should be taken to preserve it, even if it should become detached.

\section{IAPANESE CAMPHOK}

TIIE United States Consul at Osaka gives in a recent report the following particulars, reprinted from the November number of the Board of Trade Journal, respecting the Japanese camphor trade :- -

The camphor trec, from which the resinous gum is distilled, is a species of the laurel, and is found in the provinces of Tosa, Hiug:t, and Satsuma, in the south of Japan. Jarge groves of the trees are ouned by the Japanese Government, the wood heing very desirable for shipbuilding. The clistricts in which the camphor tree is found are mountainous and situated far from the sea. No reliable information can be obtained as to the cost of producing the gum before being transported in junks to IIiogo. The peasants who engage in distilling the roots and branches of the trees are said to be poor, and employ the rudest machinery.

The market value of crude camphor yum and of oil of camphor per picul ( 133 .' Ibs.) during the past year was as follows :Drained, 38.25 dols. : wet, 37.00 dols.; old dry, 43.50 dols.; average, $36 \cdot 50$ dols. ; camphor oil, $5^{\circ} 25$ dols.

The highest and lowest prices during the same period were as follow's :- Highest, 40.00 dols. ; lowest, 33.00 dols.

Camphor gum is exported in tubs measuring about 6.1 cubic feet ; oil in kerosene tins and cases. The grades are from old dry down to new wet, and the various grades depend upon the quantity of adulteration. In oil there are two grades-white and brown.

Ailulteration is practised for the most part by adding water and oil just as far as the buyer will tolerate. In some cases 20 lbs. of water will run out of a tub in twelve hours. The unadulterated article, known as the good old dry, can sometimes be bought. 'The only system of tests in determining value of the difierent gualities is by burning and by absolute spirit. The percentage of pure camphor which the crude yields when refined varies according to the quality of the crude. The average percentage of gum produced from the wood as compared with the original weight of the wood cannot be accurately ascertained here, the only foreigner known to have visited the camphor districts having declined to furnish any information on the subject.

The total exports of camphor from Hiogo during $189 \mathrm{I}$ in callies of $1 ! 1 \mathrm{~s}$ s. each amountell to $3,850,400$ catties consigned (1) the following destinations: Furope (countries not specified), $1,777,3$ co catties; london, 335,600 catties; Germany, 209,200 catties; United States, 1,277,000 catties; China, 51,900 calties ; France, 199,400 catties.

As regards the manufacture of camphor the following particulars are extracted fro:n a report by the United States Consul at Nayasaki.

Camphor is found alike on high elevations and in the valleys and lowlands. It is a hardy, vigorous, long-lived tree, and flourishes in all situations.

Many of these trees attain an enormous size. There are number in the vicinity of Nagasaki which measure Io and $12 \mathrm{ft}$. in diameter. The ancient teinple of Osuwa, at Nagasaki, is situated in a magnificent grove of many hundred grand old camphor trees, which are of great age and size, and are still beautiful and vigorous. It is stated that there are trees at other places in Kiu Shiu measuring as much as $20 \mathrm{ft}$. in diameter. the body or trunk of the tree usually runs up 20 and $30 \mathrm{ft}$. without limbs, then branching out in all directions, forming a wellproportioned, beautiful trec, ever green and very ornamental.

The leaf is small, elliptical in shape, slightly serrated, and of a vivid dark-green colour all the year round, except for a week or two in the early spring, when the young leaves are of a delicate, tender green. The seeds or berries grow in clusters and resemble black currants in size and appearance. The wood is used for many purposes, its fine grain rendering it especially valuable for cabinet-work, while it is used also for shipbuilding. The roots make excellent knees for ships.

In the manufacture of camphor the tree is necessarily destroyed, but, by a stringent law of the land, another is planted 
in its stead, The simple method of manufacture employed by the natives is as follows:-

The tree is felled to the earth and cut into small pieces, or, more properly speaking, into chips.

A large metal pot is partially filled with water and placed over a slow fire. A wooden tub is fitted to the top of the pot, and the chips of camphor wood are placed in this. The botton of the tub is perforated so as to permit the steam to pass up among the chips.

A steam-tight cover is fitted on the tub. From this tub a bamboo pipe leads to another tub, through which the enclosed steam, the generated camphor and oil flow. This second tub is connected in like manner with a third. The third tub is divided into two compartments, one above the other, the dividing floor being perforated with small holes, to allow the water and oil to pass to the lower compartment. The upper compartment is supplied with a layer of straw, which catches and holds the camphor in crystal in deposit as it passes to the cooling process. The camphor is then separated from the straw, packed in wooden tubs of $133 \frac{1}{3} \mathrm{lbs}$. each, and is ready for market.

After each boiling the water runs off through a faucet, leaving the oil, which is used by the natives for illuminating and other purposes.

\section{UNIVERSITY AND EDUCATIONAL}

\section{INTELLIGENCE}

CAMBridge.-Mr. W. Ridgeway, late Professor at Queen's College, Cork, has been elected to the Disney Professorship of Archæology for the customary period of five years. Prof. Ridgeway's recent work on the origins of weights and measures have made him well known as a scientific archæologist.

Mr. R. T. Glazebrook, F.R.S., Assistant Director of the Cavendish Laboratory, has been appointed a member of the Financial Board ; Mr. Lewis, Professor of Mineralogy, and Dr. Gaskell, F.R.S., have been elected members of the General Board of Studies ; and Mr. E. W. MacBride, Scholar of St. John's College, has been appointed Demonstrator in Animal Morphology, in the place of Mr. J. J. Lister, of the same Col lege.

The Museums and Lecture Rooms Syndicate propose to introduce the electric light into the dissecting-room of the Anatomy school, the lecture room, and histology class-room of the Department of Physiology, and the Philusophical Library, at an expense not exceeding $f$ roo.

By the death, on November 30 , of Dr. F. J. A. Hort, Lady Margaret Professor of Divinity, the University has lost not only a great theologian, but a distinguished student of science. Dr. Hort was second to Prof. Liveing in the Natural Sciences Tripos of 1851 , the first ever held. He received the mark of distinction in Physiology and in Botany. In 1856 , and again in 1871 , he was an examiner for Honours in thï Tripos. Throughout his life hi interest in the scientific progress of the University was deep and hearty.

A Syndicate has been appointed to consider the whole question of the times of holding Tripos examinations, and the changes that would follow if these were altered. The disadvantages of the present system, by which much of the benefit of the Easter term and of the Long Vacation are lost to students and teachers alike, have of late been forcibly brought before the Senate. It is to be hoped that, by bringing about a rational "Easter" or otherwise, the Syndicate's efforts may lead to a reformation.

\section{SCIENTIFIC SERIALS.}

American Meteorological Journal, November, 1892.-Wind measurement by $\mathrm{H}$. W. Dines. The two instruments generally in use, viz. the Robinson cu $\rho$ anemometer and the pressure plate, are both more or less unsatisfactory in obtaining the extreme pressure. The wind never blows uniformly, whereas the instruments are calibrated on the supposition that it does so. And the method of exposure is often unsatisfactory ; any obstacle to the free circulation of the wind either at the side or even behind or below the anemometer, vitiates the results. The usual factor $k$ for conversion of velocity to pressure in the equation $\mathrm{P}=k v^{2}$ is too high. The value ${ }^{\circ} \mathrm{CO} 5$ was given originally in a book on engineering, with a footnote stating that the experiments on

NO. 1206 , VOL. 477 which it rested were doubtful, but it has since been copied without the note. Recent experiments show that 003 is probably more correct, but with such a varying element as the wind, any factor is of little use in deducing extreme pressures from velocity anemometers. Instruments of different sizes give different results, and those calibrated by indoor trials give more wind than those tested out of doors. In some respects it is more desirable to register the pressure than the velocity, but a pressure plate which is to register 3 olb. per square foot is hardly suitable to record so small a force as one ounce, so that on many days no sign of motion is given. The author concludes from many careful experiments that the tube form of anemometer is most likely to give satisfactory results, as, apart from electricity, it is the only kind in which the motion or pressure can be transmitted to a distance without loss by friction. In this instrument the registering apparatus is placed away from the part exposed to the wind -The storms of India, by S. M. Ballou. In this article, which is a continuation of previous papers, the author treats of the storms which accompany the winter and summer rains.- The first aerial voyage across the English Channel, by $R$. de C. Ward. This voyage was successfully carried out by Dr. Jeffries and M. Blanchard on January 7,1785 . The balloon left Dover at Ih. p.m., and descended a few minutes before $4 \mathrm{~h}$. p.m., not far from Ardres. - On the production of rain, by Prof. C. Abbe. The author reviews the natural process of the formation of rain, viz. saturation by aqueous vapour, condensation into visible particles, and the aggl mmeration of these into drops large enough to be precipitated. The problem of artificial formation of rain will be partially solved if some method is invented to bring about a sudden formation of large drops out of the moist air that exists between the small particles of every cloud.

\section{SOCIETIES AND ACADEMIES.}

PARIS.

Academy of Sciences, November 28.-M. d'Abbadie in the chair.--Note accompanying the presentation of a work on the new methods of the "Mécanique Céleste," by M. Poincaré. -On the existence of distinct nervous centres for the perception of the fundamental colours of the spectrum, by M. A. Chauveau. If one goes to sleep on a seat placed obliquely in front of a window which allows the light from white clouds to fall equally on both eyes, the coloured objects in the room appear illuminated by a bright green light during a very short interval when the eyelids are opened at the moment of awakening. The phenomenon is not observed except at the moment of awakening from a profound sleep. From this it is concluded that there are distinct perceptive centres for the green, and probably also for the violet and the red. Of these, the green centres are those which first regain their activity on awakening. - Note on the observatory of Mont Blanc, by M. J. Janssen.-On the laws of expansion of liquids, their comparison with the laws relating to gases, and the form of the isothermals of liquids and gases, by E. H. Amagat. The substances examined were water, ether, alcohol, carbon bisulphide, bydrogen, nitrogen, air, oxygen, ethylene, and carbonic acid, the pressures ranging from 50 to 3000 almospheres, and the temperatures from $0^{\circ}$ to $200^{\circ}$. For both liquids and gases, the isothei mals present a slight curvature turned towards the axis of abscissæ. The angular coefficient increases with the temperature. This effect is specially pronounced in the liquids, where it corresponds to a widening-out of the network, well exemplified in carbonic acid, in the part corresponding to the lower temperatures. This widening out gradually disappears as the temperature rises; in the lighter gases, the variation with the temperature is very small. - Observations of Holmes's comet ("f" I892), made at the Paris Observatory (west equatorial), by M. O. Callandreau. - On a remarkable solar protuberance observed at Rome on November I6, 1892, by M. P. Tacchini.On universal invariants, by M. Rabut.-On straight-line congruences, by M. E. Cosserat.-On the passage of a wave through a focus, by M. P. Joubin. An apparatus for showing the complementary character of transmitted and reflected Newton's rings is mounted vertically, and illuminated by a small bright point placed at a distance of $120 \mathrm{~m}$. along the axis of symmetry. On moving a microscope along the axis of reflection the rings first appear with a black centre, which changes into white at the first focus of reflection, and again into black at the second. - On the depression of the zero, observed in boiled thermometers, by M. L. C. Baudin. The secular 